\title{
Новые данные о видовом составе и биологических характеристиках рыб озер г. Мурманск
}

\author{
Зубова Е.М., Терентьев П.М., Постнова С.В. \\ Институт проблем промышленной экологии Севера ФИЦ КНЦ РАН, Anamuты, zubova@inep.ksc.ru
}

Аннотация. Впервые исследованы ихтиоценозы пяти озер в черте г. Мурманск. Полученный видовой состав рыб показал разнотипность изученных водоемов: встречались сигово-лососевые и окуневые озера, в некоторых водоемах ядром ихтиоценоза были окунь и щука. Анализ биологических характеристик рыб из этих озер выявил значимые различия в линейно-весовых характеристиках окуня. Полученные различия обусловлены не только естественными причинами, но и влиянием антропогенных процессов, в частности эвтрофированием «городских» озер. На основе проведенных исследований оз. Семеновское можно рассматривать в качестве типичного «городского» водоема в разработке системы комплексного гидробиологического мониторинга, включая рыб. То же самое касается оз. Большое, но с точки зрения наличия сигово-лососевого комплекса.

Ключевые слова: г. Мурманск, «городские» водоемы, ихтиоценоз, биологические характеристики.

\section{New data on the species composition and biological characteristics of fish in lakes from Murmansk}

\author{
Zubova E.M., Teretjev P.M., Postnova S.V. \\ Institute of the North Industrial Ecology Problems KSC RAS, Apatity, zubova@inep.ksc.ru
}

\begin{abstract}
The ichthyocenoses of five lakes within the Murmansk city were studied for the first time. The resulting species composition of fish showed the diversity of the studied water bodies: whitefish-salmon and perch lakes were found, in some water bodies perch and pike were the core of the ichthyocenosis. Analysis of the biological characteristics of fish from these lakes revealed significant differences in the linear-weight characteristics of the perch. The differences obtained are due not only to natural causes, but also to the influence of anthropogenic processes, in particular the eutrophication of «urban» lakes. On the basis of the conducted studies of the Semenovskoye Lake can be considered as a typical «urban» reservoir in the development of a system of integrated hydrobiological monitoring, including fish. The same applies to Bolshoe Lake, but from the point of view of the presence of a whitefish-salmon complex.
\end{abstract}

Key words: Murmansk, «urban» reservoirs, ichthyocenosis, biological characteristics.

\section{введение}

В связи с интенсивным развитием промышленности на территории Мурманской области и усилением антропогенного влияния на экосистемы во второй половине XX века, большое внимание исследователей было уделено рыбам, как индикаторам состояния водоемов. В основном, эти работы были посвящены ихтиофауне больших водоемов озера Имандра и бассейна реки Пасвик, на водосборной территории которых сосредоточены все крупные промышленные предприятия региона (Моисеенко, 1991; Моисеенко, Яковлев, 1990; Кашулин и др., 1999 и др.). Состояние ихтиоценозов малых водоемов урбанизированных территорий Мурманской области практически не оценивалось. В настоящее время материалы подобных работ имеются лишь для оз. Куэтсъярви (нижнее течение р. Пасвик), оз. Большой Вудъявр (бассейн р. Белая) и оз. Ковдор (бассейн р. Ёна) (Кашулин и др., 1999; Королева и др., 2012; Зубова, 2015). Мурманск - столица Мурманской области и крупнейший город мира, полностью расположенный за Полярным кругом, с населением около 300 тыс. человек. На территории Мурманска и вблизи него расположено несколько десятков озер, имеющих как хозяйственно-бытовое, так и рекреационное значение для жителей и гостей города (Слуковский и др., 2020). На основании исследований гидрохимических показателей и донных отложений некоторых озер Мурманска в 2018 - 2019 гг., их можно отнести к водоемам с высоким и крайне высоким уровнем загрязнения (Slukovskii et al., 2020). Как в воде, так и в поверхностных слоях донных отложений наблюдается повышенное содержание тяжелых металлов ( $\mathrm{V}, \mathrm{Ni}, \mathrm{Sb}, \mathrm{Pb}$, $\mathrm{Co}, \mathrm{Cr}$ и W). Основными источниками загрязнения являются выбросы Мурманской ТЭЦ, угольного 
порта, автомобильного и железнодорожного транспорта. Ихтиофауна «городских водоемов» Мурманска ранее не изучалась. Целью настоящей работы было исследование видового состава и основных биологических характеристик рыб ранее не исследованных водоемов г. Мурманск. Полученные данные необходимы для оценки особенностей функционирования экосистем «городских» водоемов Мурманска в условиях интенсивного антропогенного загрязнения и разработки системы их мониторинга.

\section{Материал и методы}

Ихтиологические исследования проводились в сентябре 2020 г. на следующих озерах г. Муранск: Большое, Семеновское, Среднее, Окуневое и Ледовое по известным методикам (Правдин, 1966). Возраст кумжи и ряпушки определяли по чешуе, окуня - по жаберной крышке, щуки - по клейтруму (Чугунова, 1959). Для анализа питания рыб исследовалось содержание их желудков (Попова, Решетников 2011). Подробные гидрологические и гидрохимические характеристики исследованных озер приведены в работе Slukovskii et al., 2020

\section{Результаты}

Оз. Большое $\left(68.975502^{\circ} \mathrm{N}, 33.160240^{\circ} \mathrm{E}\right)$. В уловах присутствовали кумжа Salmo trutta L. (15 экз.) и ряпушка Coregonus albula (L.) (1 экз.). Кумжа была представлена особями длиной 149-233 мм и массой 35-139 г. Особенности распределения кумжи по длине и массе показаны на рис. 1 a, б. Возрастная структура кумжи из оз. Большое состоит из 4 возрастных групп (от $2+$ лет до $5+$ лет), преобладали рыбы в возрасте $3+-4+$ лет (рис. 1 в). Линейный и весовой рост кумжи показан на рисунке 1 г. Несмотря на невысокие линейно-весовые характеристики кумжи в озере, половые продукты двух самок были на IV стадии развития. Длина половозрелых рыб составила 194 и 231 мм, масса - 76 и 139 г соответственно. Кумжа в оз. Большое в основном питалась личинками ру-

(a)

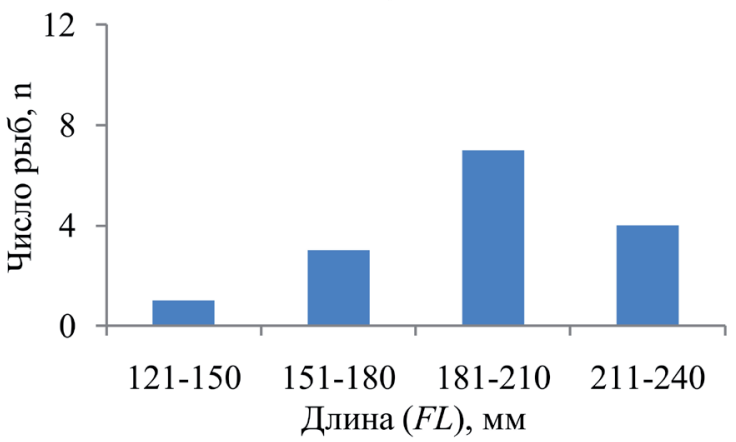

(в)

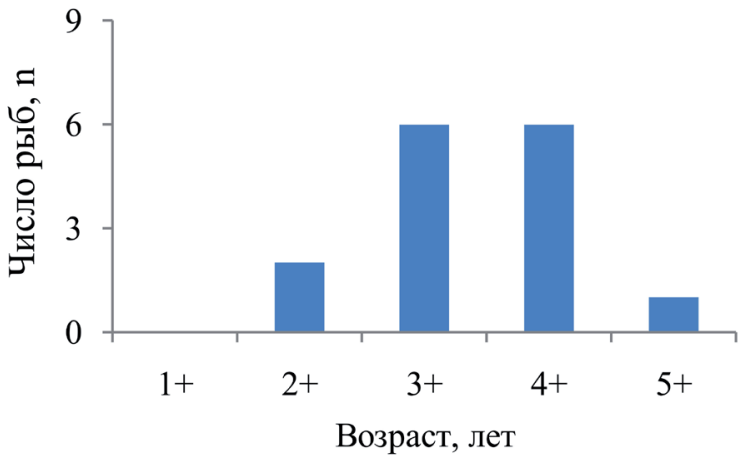

(б)

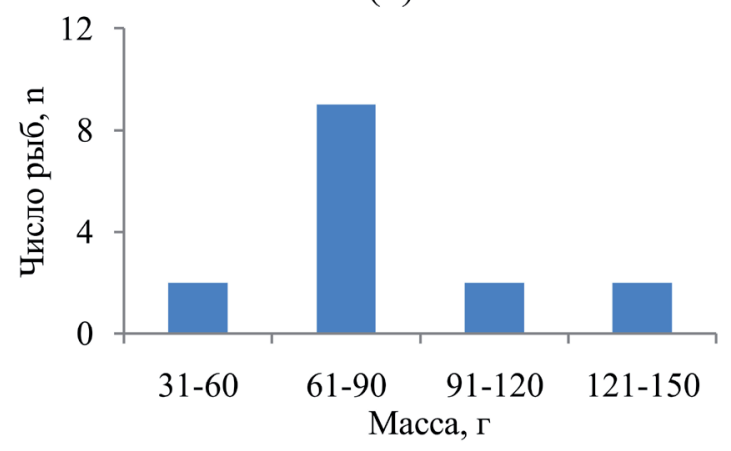

(г)

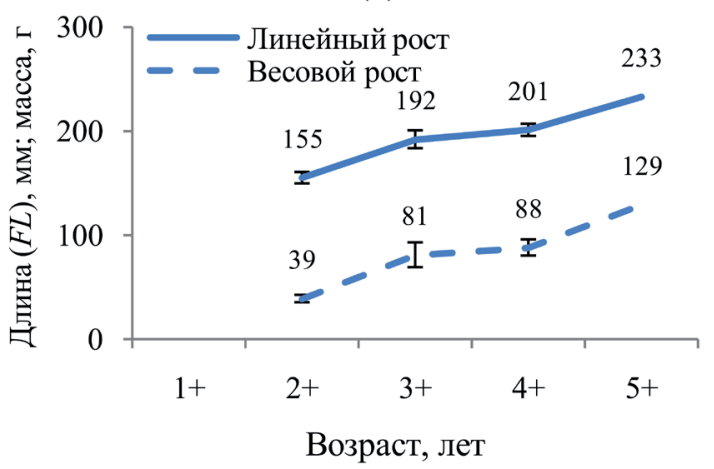

Рис. 1. Размерный $(F L)$, мм (а), весовой, г (б) и возрастной составы (г), линейный $(F L)$, мм и весовой, г рост кумжи в оз. Большое, 2020 г.

Fig. 1. Dimensional (FL), mm (a), weight, g (b) and age composition (d), linear (FL), mm and weight, g growth of brown trout in the lake. Big, 2020. 
(a)

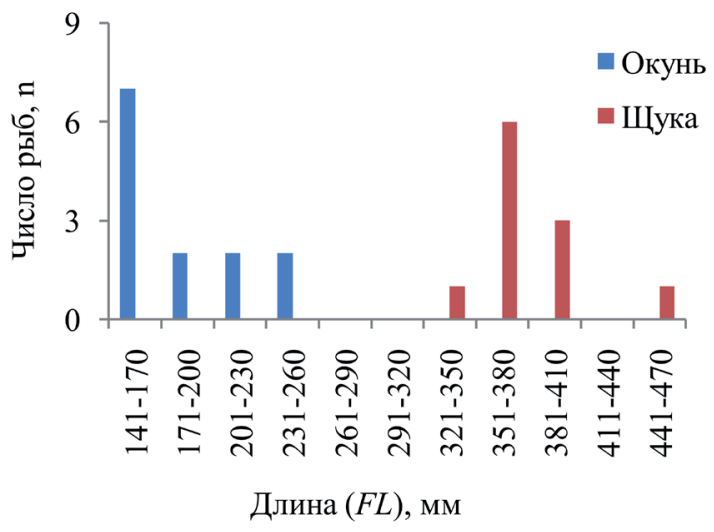

(в)

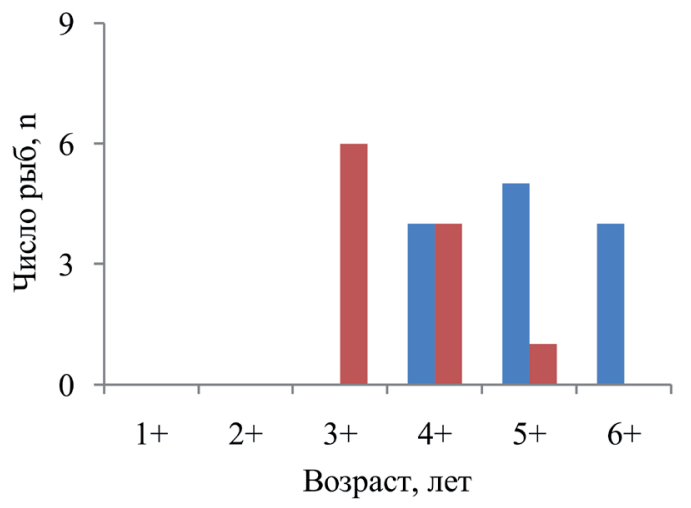

(б)

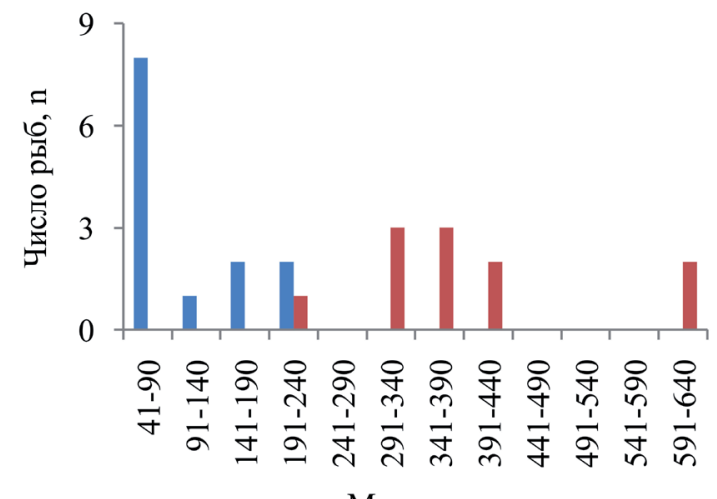

$(\Gamma)$

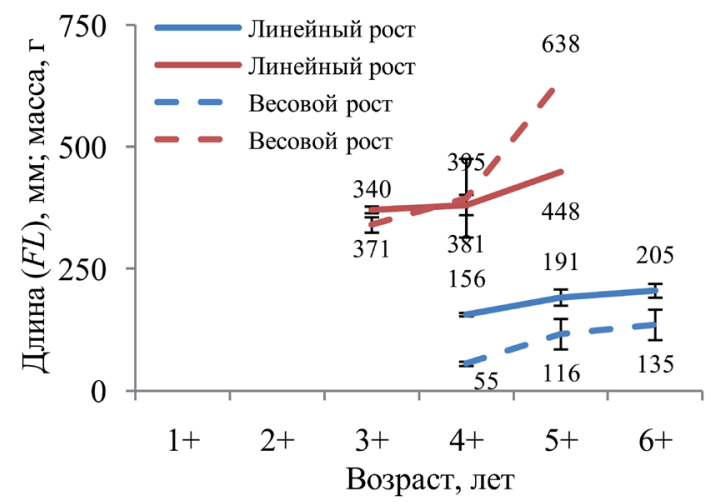

Рис. 2. Размерный $(F L)$, мм (а), весовой, г (б) и возрастной составы (г), линейный $(F L)$, мм и весовой, г рост окуня и щуки в оз. Семеновское, 2020 г.

Fig. 2. Dimensional (FL), mm (a), weight, g (b) and age composition (d), linear (FL), mm and weight, g growth of perch and pike in the lake. Semenovskoe, 2020.

чейников (рода Limnephilus, Molanna и Phryganea): индекс относительной значимости (далее IR) составил $93.0 \%$. В желудках двух особей (длиной 174 и 186 м) была обнаружена трехиглая колюшка Gasterosteus aculeatus L. (6.9 \% IR). Также в желудках кумжи выявлены имаго отрядов Хирономиды (семейства Limoniidae и Tipulidae) и Полужесткокрылые (Cicadellidae).Размерно-весовые показатели ряпушки оз. Большое, представленной преднерестовым самцом в возрасте 4+, не превышали 155 мм и 33 г.

Озеро Семеновское $\left(68.991553^{\circ} \mathrm{N}, 33.089911^{\circ} \mathrm{E}\right)$. Выборки из озера включали два вида рыб речного окуня Perca fluviatillis L. (13 экз.) и щуку Esox lucius L. (11 экз.). Окунь был представлен особями длиной 145-239 мм и массой 42-213 г, Аналогичные показатели щуки варьировали в пределах 325-448 мм и 210-638 г. Распределение окуня и щуки по длине и массе показано на рисунке $2 \mathrm{a}, 6$. Окунь был представлен особями в возрасте от $4+$ до $5+$ лет, щука - от $3+$ до $5+$ лет. В выборке доминировали рыбы в возрасте $5+$ и $3+$ лет соответственно (рис. 2 в). Линейный и весовой рост окуня и щуки показан на рисунке 2 г. 46 \% особей выловленного окуня (как самцы, так и самки) имели стадию развития гонад III - IV. Длина половезрелых окуней составила 158-209 мм, масса - 52-213 г.

Среди щук только 2 особи (длиной 425 и 448 мм, массой 601 и 638 г) имели гонады на III стадии развития. В желудках у питающихся особей щуки был обнаружен окунь. В питании окуня большое значение имел крупный зоопланктон (Eurycercus, Sida) - $96.5 \%$ IR. Также окунь питался личинками хирономид (Chironomus) и ручейников (Phryganea), брюхоногими моллюсками (Valvata) и клопами (Sigara). У одного окуня длиной 236 мм в желудке обнаружена рыба (окунь).

Озеро Окуневое $\left(68.950427^{\circ} \mathrm{N}, 33.128116^{\circ} \mathrm{E}\right)$. В озере был отмечен только речной окунь (11 экз.). Он имел меньший диапазон значений длины и массы, нежели окунь из оз. Семеновское 
(a)

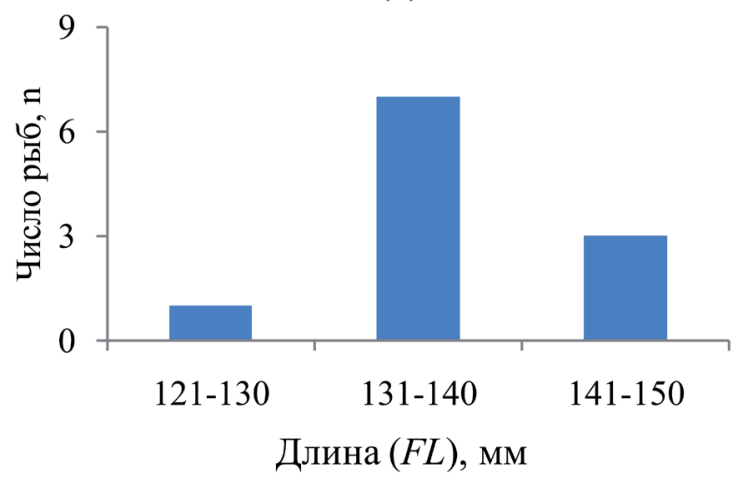

(B)

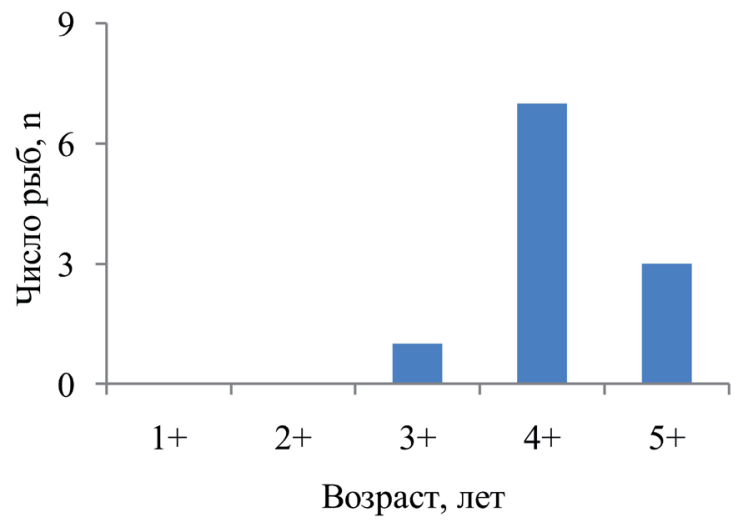

(6)

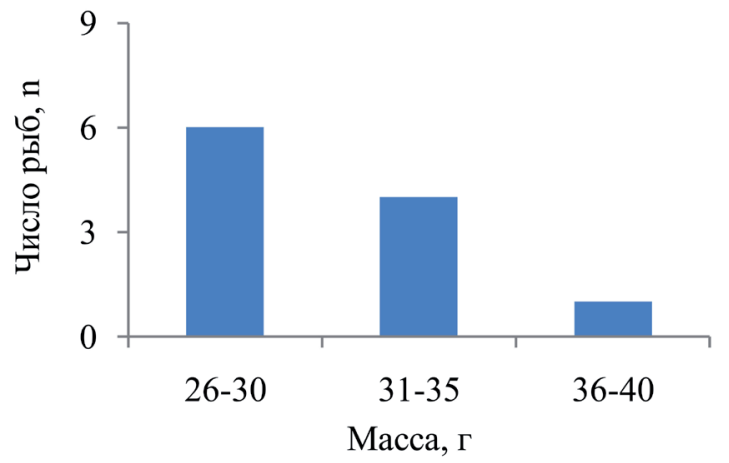

(г)

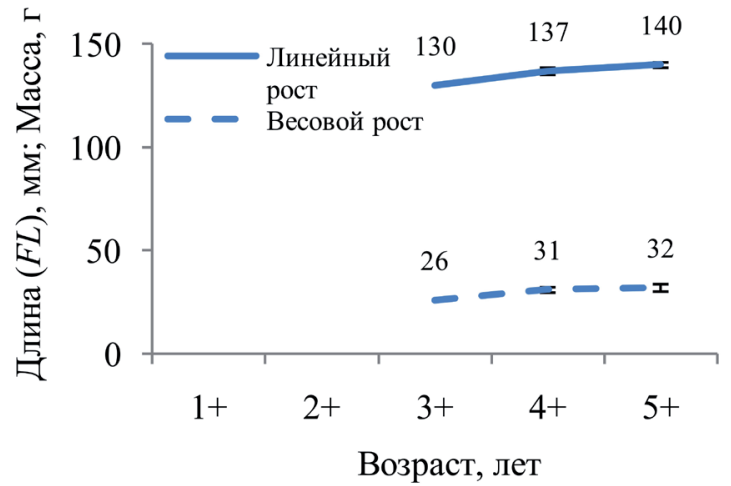

Рис. 3. Размерный $(F L)$, мм (а), весовой, г (б) и возрастной составы (г), линейный $(F L)$, мм и весовой, г рост окуня в оз. Окуневое, 2020 г.

Fig. 3. Dimensional (FL), mm (a), weight, g (b) and age composition (d), linear $(F L)$, mm and weight, g perch growth in the lake. Okunevoye, 2020.

(см. выше): 130-147 мм и 26-38 г соответственно (рис. 3 а, б). Окунь в уловах был представлен особями в возрасте от $3+$ до $5+$, наиболее многочисленными были особи в возрасте $4+$ лет (рис. 3 г). Линейный и весовой рост окуня из оз. Окуневое был значимо ниже $(p=0.001)$ по сравнению с оз. Семеновское (рис. 2 г, 3 г). 91 \% особей окуня из Окуневого имели хорошо развитые половые продукты. У двух исследованных на питание окуней в желудках были обнаружены личинки хирономид (Chironomus и Procladius), зоопланктонные организмы (Eurycercus) и водяные клопы (Sigara).

В озерах Среднее $\left(68.981130^{\circ} \mathrm{N}, 33.121181^{\circ} \mathrm{E}\right)$ и Ледовое $\left(68.933005^{\circ} \mathrm{N}, 33.105182^{\circ} \mathrm{E}\right)$ в сетных орудиях лова рыба отсутствовала.

В прибрежной части всех исследованных озер г. Мурманска обнаруживались скопления девятииглой колюшки Pungitius pungitius L. и, учитывая питание рыб, в оз. Большое обитает трехиглая колюшка.

\section{Обсуждение}

Таким образом, предварительные исследования ихтиоценозов озер г. Мурманска, показали их разнотипность. Оз. Большое возможно отнести к сигово - лососевому водоему: ядро ихтиоценоза составляют осеннезимненерестующие кумжа и сиги. Причем, кумжа здесь, по всей вероятности, образует жилую озерную (или озерно - речную) форму, созревающую при значимо меньших размеpax и возрасте $(3+-4+$ лет), нежели проходная кумжа (Шустер, 1985). Кумжа в оз. Большое является типичным бентофагом и в незначительной мере хищником.

Ядром ихтиоценоза оз. Семеновское являются ранневесеннерестующие щука и окунь. В желудках окуня из Семеновского в основном обнаруживался крупный ракообразный зоопланктон. Присутствие в составе пищевого комка окуня организмов бентоса и рыбы, говорит об эврифагии 
окуня в Семеновском или смешанном питании с проявлением каннибализма у более крупных особей. Щука в данном озере является типичным хищником.

Оз. Окуневое является окуневым водоемом. Окуни здесь имеют смешанное питание и имеют значимо меньшие темпы наблюденного линейно - весового роста относительно окуня из оз. Семеновское. Высокие темпы роста окуня из Семеновского связаны с большей продуктивностью озеpa, нежели Окуневое, вызванной его антропогенным загрязнением (Черепанов, Денисов, Слуковский, 2020).

Отсутствие промысловых видов рыб в оз. Ледовое объясняется сильным загрязнением водоема (Slukovskii et al., 2020). Кроме того, чрезвычайно малые размеры озера при отсутствии выраженной литорали, участков высшей водной растительности, а также закрытость водоема препятствуют возможности функционирования в нем типичных для арктических систем видов рыб. Очевидно, что отсутствие проточности оз. Среднее также препятствует развитию и воспроизводству в нем представителей фауны рыб, поскольку по гидрологическим показателям оно больше относится к гольцовым водоемам.

На основе вышеизложенного оз. Семеновское можно рассматривать в качестве типичного «городского» водоема в разработке системы комплексного гидробиологического мониторинга, включая рыб. То же самое касается оз. Большое, но с точки зрения наличия сигово-лососевого комплекса.

Работа поддержана из средств гранта РНФ № 19-77-10007.

\section{Литература}

1. Зубова Е.M. Линейный рост европейского сига Coregonus lavaretus (L.) в антропогенно-модифицированных водоемах европейской субарктики (на примере Мурманской области): Автореф. дис. ... к.б.н. Пермь. Изд-во: ПГНИУ. 2015. 28 с.

2. Кашулин Н.А., Лукин А.А., Амундсен П.А. Рыбы пресноводных вод Субарктики как биоиндикаторы техногенного загрязнения. Апатиты. Изд-во: КНЦ РАН. 1999. 142 с.

3. Королева И.М., Валькова С.А., Вандыш О.И., Денисов Д.Б., Терентьев П.М., Сандимиров С.С., Даувальтер В.А., Кашулин Н.А. Состояние экосистемы озера Ковдор и характеристика рыбной части его населения // Труды КНЦ РАН. Прикладная экология Севера. Апатиты. Изд-во: КНЦ РАН. 2012. Вып. 2. № 3 (10). C. 100-132 .

4. Моисеенко Т.И. Закисление и загрязнение тяжелыми металлами поверхностных вод Кольского Севера. Апатиты. Изд-во: КНЦ РАН. 1991. 47 с.

5. Моисеенко Т.И., Яковлев В.А. Антропогенные преобразования водных экосистем Кольского Севера. Л. Изд-во: Наука. 1990. 219 с.

6. Попова О.А., Решетников Ю.С. О комплексных индексах при изучении питания рыб // Вопросы ихтиологии. 2011. Т. 51. № 5. С. 1-6.

7. Правдин И.Ф. Руководство по изучению рыб. М. Изд-во: Пищ. пром-сть. 1966. 376 с

8. Слуковский 3.И., Даувальтер В.А., Гузева А.В., Денисов Д.Б., Черепанов А.А. Природные и техногенные факторы в формировании геохимии современных донных отложений малых озер г. Мурманска (Арктическая зона РФ) // Труды Ферсмановской научной сессии ГИ КНЦ РАН. 2020. № 17. С. 510-514. https://doi.org/10.31241/FNS.2020.17.098.

9. Черепанов А.А., Денисов Д.Б., Вандыш О.И., Слуковский 3.И., Постнова С.В. Исследования сообществ зоопланктона в озерах города Мурманска // Труды КНЦ РАН. 2019. 4(10). С. 83-93. DOI: 10.25702/ KSC.2307-5252.2019.4.83-93.

10. Чугунова Н.И. Руководство по изучению возраста и роста рыб. М. Изд-во: АН СССР. 1959. 64 с.

11. Шустер Б.И. Сиг Coregonus lavaretus pidschian (Gmelin) Верхнетуломского водохранилища // Рыбохозяйственные исследования Верхнетуломского и Серебрянского водохранилищ Мурманской области: Сб. научных трудов. Мурманск. Изд-во: ПИНРО. 1985. С. 58-71.

12. Slukovskii Z., Dauvalter V., Guzeva A., Denisov D., Cherepanov A., Siroezhko E. The Hydrochemistry and Recent Sediment Geochemistry of Small Lakes of Murmansk, Arctic Zone of Russia // Water. 2020. V. 12. P. 1130. https://doi.org/10.3390/w12041130. 